Pesq. Vet. Bras. 35(7):691-699, julho 2015 DOI: $10.1590 / \mathrm{S} 0100-736 \mathrm{X} 2015000700015$

\title{
Ação trófica de aditivos fitogênicos, glutamina e ácido glutâmico sobre a Bursa de Fabrícius e intestino delgado de frangos de corte ${ }^{1}$
}

\author{
Vanessa Cristina Pelícia ${ }^{2 *}$, Carlos Ducatti ${ }^{3}$, Priscila Cavalca de Araujo ${ }^{2}$, \\ Ana Cristina Stradiotti ${ }^{2}$, Monica Megumi Aoyagi ${ }^{2}$, Barbara da Silva Fernandes ${ }^{2}$, \\ Evandro Tadeu Silva ${ }^{3}$ e José Roberto Sartori ${ }^{2}$
}

\begin{abstract}
Pelícia V.C., Ducatti C., Araujo P.C., Stradiotti A.C., Aoyagi M.M., Fernandes B.S., Silva E.T. \& Sartori J.R. 2015. [Trophic action of phytogenic additives, glutamine and glutamic acid on Bursa Fabricii and small intestine of broilers.] Ação trófica de aditivos fitogênicos, glutamina e ácido glutâmico sobre a Bursa de Fabrícius e intestino delgado de frangos de corte. Pesquisa Veterinária Brasileira 35(7):691-699. Faculdade de Medicina Veterinária e Zootecnia, Universidade Estadual Paulista, Distrito de Rubião Júnior s/n, Botucatu, SP 18618-970, Brazil. E-mail: vcpelicia@yahoo.com.br

The aim of this study was to evaluate the effect of phytogenic additives and glutamine plus glutamic acid, associated or not, on histomorphometry of bursa of Fabricius and small intestine, oocyst count and lesion scores, and carbon turnover of duodenal mucosa of broiler chickens infected with Eimeria acervulina. A total of 450 male broiler chickens was distributed into a completely randomized design with six treatments and three replications. Treatments consisted of control diet (CD); $C D+$ coccidiosis vaccine; $C D+$ antibiotic performance enhancers and anticoccidial (APE/AC); $\mathrm{CD}+$ glutamine and glutamic acid (Gln/Glu); $\mathrm{CD}+$ phytogenic additives (PA); $\mathrm{CD}+\mathrm{Gln} / \mathrm{Glu}+\mathrm{PA}$. Birds on treatment $\mathrm{CD}+$ vaccine were vaccinated via drinking water at three days of age against coccidiosis. At 16 days of age all birds of all treatments were inoculated orally and individually with 500,000 oocysts of Eimeria acervulina. There was no treatment effect on lesion score in the intestinal epithelium of birds. The smaller number of excreted oocysts was observed in groups of birds fed diets containing APE/AC and PA. Were observed better results of villus height and crypt depth for duodenum and ileum of birds of treatments containing Gln/Glu at 7 days of age, and Gln/Glu and PA at 21 days of age. Higher percentage of cortical area from bursa follicles was observed in birds fed diets supplemented with Gln/Glu and PA at 7, 14 and 21 days of age. Increased turnover of intestinal mucosa was observed in treatments containing Gln/ Glu, indicating acceleration in development and regeneration of damaged tissue. Glutamine plus glutamic acid and phytogenic additives can provide improvements to structure, and thus to intestinal function, as well as to better immune response against the infectious challenges. Phytogenic additives can be used for coccidiosis control of broiler chickens where the use of antibiotic performance enhancers and anticoccidials is prohibited.
\end{abstract}

INDEX TERMS: Glutamine, glutamic acid, Bursa Fabricii, small intestine, coccidiosis, lesion score, stable isotope, turnover.

\footnotetext{
${ }^{1}$ Recebido em 11 de outubro de 2014.

Aceito para publicação em 8 de julho de 2015.

${ }^{2}$ Faculdade de Medicina Veterinária e Zootecnia, Universidade Estadual Paulista (Unesp), Distrito de Rubião Júnior s/n, Botucatu, SP 18618-970, Brasil. *Autor para correspondência: vcpelicia@yahoo.com.br

${ }^{3}$ Instituto de Biociências, Unesp, Distrito de Rubião Júnior, s/n, Botucatu, SP 18600-000.
}

RESUMO.- 0 objetivo deste trabalho foi avaliar o efeito dos aditivos fitogênicos e da glutamina mais ácido glutâmico, associados ou não, sobre a histomorfometria da Bursa de Fabricius e intestino delgado, sobre contagem de oocistos e escores de lesão e sobre o turnover do carbono da mucosa intestinal de frangos de corte experimentalmente infectadas com Eimeria acervulina. Para isso foram utilizados 
450 pintos de corte machos distribuídos em delineamento inteiramente casualisado, com seis tratamentos e três repetições. Os tratamentos consistiram de dieta controle (DC); DC + Vacina de coccidiose; DC + antibióticos melhoradores de desempenho e anticoccidiano (AMD/AC); DC + glutamina e ácido glutâmico (Gln/Glu); DC + sditivos fitogênicos (AFs); DC + Gln/Glu + AFs. As aves do tratamento DC + Vacina foram vacinadas via água de bebida, aos três dias de idade, contra coccidiose. Aos 16 dias de idade todas as aves de todos os tratamentos foram inoculadas oralmente e individualmente com 500.000 oocistos de Eimeria acervulina. Não houve efeito dos tratamentos para escore de lesão no epitélio intestinal das aves. 0 menor número de oocistos excretados foi observado nos grupos de aves alimentadas com dieta contendo AMD/AC e AFs. Foram observados melhores resultados para altura das vilosidades e profundidade das criptas do duodeno e ílio das aves dos tratamentos contendo Gln/Glu, aos 7 dias de idade e Gln/Glu e AFs aos 21 dias de idade. Maior porcentagem de área cortical dos folículos bursais foi observada em aves alimentadas com dieta suplementada com Gln/Glu e AFs aos 7, 14 e 21 dias de idade. Maior turnover da mucosa intestinal foi observada em aves dos tratamentos contendo Gln/Glu, indicando aceleração do desenvolvimento e regeneração do tecido lesado. Glutamina mais ácido glutâmico e aditivos fitogênicos podem oferecer melhorias à estrutura e, consequentemente, à função do intestino, bem como melhores condições para resposta imune frente à desafios infecciosos. Aditivos fitogênicos podem ser utilizados no controle da coccidiose em criações de frangos de corte onde é proibida a utilização de antibióticos melhoradores de desempenho e anticoccidianos.

TERMOS DE INDEXAÇÃO: Glutamina, ácido glutâmico, Bursa Fabricii, intestino delgado, coccidiose, escores de lesão, isótopos estáveis, turnover.

\section{INTRODUÇÃO}

A integridade das células epiteliais da mucosa gastrintestinal é de vital relevância para o bom desempenho das aves (Maiorka et al. 2002). Distúrbios na microbiota normal ou nas células epiteliais intestinais, causados por algum tipo de estresse, patógenos ou substâncias químicas, podem alterar a permeabilidade desta barreira natural, facilitando a invasão de patógenos e outras substâncias nocivas, diminuindo a capacidade de digestão e absorção de nutrientes e causando ainda inflamações crônicas na mucosa intestinal (Podolsky 1993).

Com a finalidade de controlar agentes prejudiciais aos processos de digestão e absorção dos nutrientes, antibióticos e quimioterápicos têm sido adicionados nas dietas dos animais, promovendo melhoras nos índices zootécnicos e de produção. Porém, diante da crescente proibição da utilização de antibióticos e da pressão por parte dos consumidores e grupos ativistas a favor da proibição total de qualquer antimicrobiano como melhorador de desempenho na produção de animais destinados à alimentação, torna-se necessária busca por aditivos naturais alternativos que auxiliem, através de mecanismos específicos, a superar desafios sanitários.

Fatores estressantes também influenciam negativamente o sistema imune dos animais de criação e, dessa forma, implicam em aumento da susceptibilidade às doenças, e conse- quentemente quedas no desempenho (Dohms \& Metz 1991). O sistema imune das aves possui um órgão linfoepitelial (Bursa de Fabricius), onde ocorrem a diferenciação e maturação dos linfócitos B, responsáveis pela produção de anticorpos. Estudos histomorfométricos da Bursa de Fabricius em aves submetidas a condições de estresse concluíram que o estresse afeta o desenvolvimento e maturação das bursas com aumento no índice de apoptose dos linfócitos (Guimarães 2001).

Pesquisadores têm demonstrado que glutamina e ácido glutâmico (Yoo et al. 1997, Newsholme 2003a, 2003b, Yi et al. 2005, Caldara et al. 2010, Nascimento et al. 2014), bem como óleos essenciais e extratos vegetais (Christaki et al. 2004, Jamroz et al. 2005, Awaad et al. 2010, Vasconcelos et al. 2010, Fascina et al. 2012) são capazes de melhorar a resposta imune e a microbiota intestinal, prevenindo efeitos negativos na estrutura do intestino, melhorar a digestão e absorção dos nutrientes e consequentemente, o desempenho dos animais, o que os tornam aditivos interessantes para criação de frangos de corte alternativos durante períodos de desafio.

Em função dos diversos efeitos benéficos destes aditivos naturais sobre a estrutura intestinal e sistema imune, o objetivo deste trabalho foi avaliar o efeito dos aditivos fitogênicos e da glutamina mais ácido glutâmico, associados ou não, sobre a histomorfometria da Bursa de Fabricius e intestino delgado, sobre contagem de oocistos e escores de lesão do epitélio intestinal e sobre o turnover da mucosa intestinal de frangos de corte experimentalmente infectadas com Eimeria acervulina.

\section{MATERIAL E MÉTODOS}

A pesquisa foi conduzida na Universidade Estadual Paulista (Unesp), Faculdade de Medicina Veterinária e Zootecnia, Campus de Botucatu, nas instalações do Laboratório de Nutrição de Aves, sendo aprovada pela Câmara de Ética em Experimentação Animal (protocolo no 07/2009 - CEEA).

Foram utilizados 450 pintos de corte machos de 1 dia de idade da linhagem Cobb, vacinados no incubatório contra doenças de Marek, Gumboro e Bouba aviária. Em câmara climática, com temperatura e ventilação controladas e mantidas na zona de conforto térmico, as aves foram alojadas em gaiolas metálicas dispostas em fileiras, munidas de comedouros frontais e bebedouros tipo nipple, nas quais foram criadas até 42 dias de idade. 0 delineamento foi inteiramente casualisado, com seis tratamentos e três repetições. Os tratamentos consistiram de dieta controle sem adição de antibióticos melhoradores de desempenho e anticoccidiano (DC); DC + antibiótico melhorador de desempenho ${ }^{4}$ e anticoccidiano ${ }^{5}$ $(\mathrm{AMD} / \mathrm{AC}) ; \mathrm{DC}+$ glutamina + ácido glutâmico ${ }^{6}$ (Gln/Glu); DC + aditivos fitogênicos ${ }^{7}$ (AFs), e; DC + Gln/Glu + AFs. As aves do tratamento Controle + Vacina foram vacinadas foram vacinadas ${ }^{8}$ individualmente e oralmente, aos três dias de idade, contra coccidiose.

\footnotetext{
${ }^{4}$ Surmax $^{\circledR} 10 \%$, Elanco (Avilamicina): 10ppm de inclusão.

${ }^{5}$ Monenpac ${ }^{\circledR}$, M Cassab (Monensina): 100ppm de inclusão.

${ }^{6} \mathrm{AminoGut}^{\circledR}$, Ajinomoto (garantia mínima de $10 \%$ de glutamina e $10 \%$ de ácido glutâmico): inclusão de 1,0\% nas fases de 1 a 21 dias de idade e $0,5 \%$ nas fases de 22 a 42 dias de idade.

${ }^{7}$ Imunostart ${ }^{\circledR}$, M Cassab (composto de extrato de cúrcuma, extratos de citros e extratos de sementes de uva): inclusão de $700 \mathrm{~g} /$ ton de 1 a 10 dias de idade; $500 \mathrm{~g} /$ ton de 11 a 21 dias de idade; Enterocox ${ }^{\circledR}$, M Cassab (composto de óleo de eucalipto, óleo essencial de Canela-da-China, folhas de Boldo-do-Chile, sementes de Feno-Grego): inclusão de $300 \mathrm{~g} /$ ton de 1 a 10 dias de idade, $1000 \mathrm{~g} /$ ton de 11 a 35 dias de idade e $500 \mathrm{~g} / \mathrm{ton}$ de 36 a 42 dias de idade.

${ }^{8}$ Livacox $^{\circledR}$, Biopharm.
} 
A inclusão do AminoGut ${ }^{\circledR}$ nas rações foi realizada em substituição ao amido de milho e a inclusão dos demais aditivos em substituição ao material inerte (caulim) de acordo com as recomendações dos fabricantes.

0 período de criação foi dividido em apenas duas fases: inicial (1-21 dias de idade) e crescimento (22-42 dias de idade) para evitar variação nos sinais isotópicos das dietas, sendo que as dietas de 1-7 e de 8-21 dias de idade diferem nos níveis de aditivos fitogênicos conforme níveis estabelecidos para cada fase de criação (Quadro 1). As exigências nutricionais das aves foram estabelecidas para cada fase de criação segundo as tabelas de exigências nutricionais de Rostagno et al. (2005). Água e ração foram fornecidas ad libitum e o programa de luz foi constante, com fornecimento de 24 horas de luz durante todo o período de criação.

Os pintos de corte foram obtidos de matrizes que estavam recebendo dietas compostas predominantemente por plantas do ciclo fotossintético $\mathrm{C}_{4^{\prime}}$ (milho). Estes, ao nascerem, possuíam em seus tecidos corporais sinais isotópicos de ${ }^{13} \mathrm{C}$ semelhantes ao destas dietas $\left(\delta^{13} \mathrm{C}=-18,65 \% 0\right)$. Após o alojamento, para avaliar o turnover da mucosa intestinal através de análise isotópica do

\section{Quadro 1. Composição das rações controle de acordo com} cada fase de criação

\begin{tabular}{|c|c|c|}
\hline Ingredientes & Inicial & Crescimento \\
\hline Arroz & 57,584 & - \\
\hline Milho & - & 61,661 \\
\hline Amido & 1,000 & 0,500 \\
\hline Farelo de soja & 34,420 & 30,870 \\
\hline Óleo de soja & 2,956 & 3,197 \\
\hline $\mathrm{NaCl}$ & 0,500 & 0,480 \\
\hline Supl. Vitamínico ${ }^{1}$ & 0,100 & 0,100 \\
\hline Supl. Mineral $^{2}$ & 0,050 & 0,050 \\
\hline Calcário calcítico & 0,810 & 0,830 \\
\hline Fosfato bicálcico & 1,900 & 1,670 \\
\hline DL-metionina & 0,155 & 0,175 \\
\hline L-lisina & 0,190 & 0,230 \\
\hline L-treonina & 0,100 & 0,060 \\
\hline Cloreto de colina $^{3}$ & 0,060 & 0,050 \\
\hline Caulim $^{4}$ & 0,175 & 0,125 \\
\hline \multicolumn{3}{|l|}{ Valores calculados } \\
\hline EM (kcal/kg) & 3000,01 & 3100,00 \\
\hline PB (\%) & 20,79 & 19,41 \\
\hline Cálcio (\%) & 0,89 & 0,83 \\
\hline Fósforo disp. (\%) & 0,44 & 0,41 \\
\hline Metionina (\%) & 0,49 & 0,48 \\
\hline Met + Cys (\%) & 0,81 & 0,79 \\
\hline Lisina (\%) & 1,26 & 1,18 \\
\hline Treonina (\%) & 0,86 & 0,81 \\
\hline Potássio (\%) & 0,74 & 0,74 \\
\hline Sódio (\%) & 0,22 & 0,21 \\
\hline Cloro (\%) & 0,34 & 0,33 \\
\hline Ác. linoléico (\%) & 2,03 & 3,06 \\
\hline \multicolumn{3}{|l|}{ Valores analisados } \\
\hline Valor isotópico ${ }^{5}$ em $\delta^{13} \mathrm{C}(\% 0)$ & $\sim-28$ & $\sim-19$ \\
\hline
\end{tabular}

${ }^{1}$ Suplemento vitamínico MCassab Tecnologia Animal (por kg de ração): vit. $\mathrm{A}=11.000 \mathrm{UI}$; vit. $\mathrm{D}_{3^{\prime}}=2.000 \mathrm{UI}$; vit. $\mathrm{E}=16 \mathrm{mg}$; vit. $\mathrm{K}_{3}=1,5 \mathrm{mg} ; \mathrm{B}_{1}=$ $1,2 \mathrm{mg}$; vit. $\mathrm{B}_{2}=4,5 \mathrm{mg}$; vit. $\mathrm{B}_{6}=2 \mathrm{mg}$; vit. $\mathrm{B}_{12}=16 \mu \mathrm{g}$; niacina $=35 \mathrm{mg}$; ac.fólico $=0,4 \mathrm{mg}$; ác.pantotênico $=10 \mathrm{mg}$; biotina $=60 \mu \mathrm{g}$; selênio $=$, $250 \mu \mathrm{g}$. (fases pré-inicial, inicial e crescimento); vit.A = 5.500 UI; vit.D3 =, 1.000 UI; vit. $\mathrm{E}=8 \mathrm{mg}$; vit. $\mathrm{K}_{3}=0,75 \mathrm{mg} ; \mathrm{B}_{1}=0,6 \mathrm{mg}$; vit. $\mathrm{B}_{2}=2,25 \mathrm{mg}$; vit. $B_{6}=$, $1 \mathrm{mg}$; vit. $\mathrm{B}_{12}=8 \mu \mathrm{g} ;$ niacina $=, 17,5 \mathrm{mg}$; ac. Fólico $=0,2 \mathrm{mg}$; ác.pantotênico $=5 \mathrm{mg}$; biotina $=30 \mu \mathrm{g}$; selênio $=125 \mu \mathrm{g}$. (fase final). ${ }^{2} \mathrm{Su}-$ plemento mineral MCassab Tecnologia Animal (por kg de ração); iodo = $1000 \mu \mathrm{g}$; ferro $=30 \mathrm{mg}$; cobre $=9 \mathrm{mg}$; manganês $=60 \mathrm{mg}$; zinco $=60 \mathrm{mg}$. ${ }^{3}$ Cloreto de colina (70). ${ }^{4}$ Veículo em substituição aos aditivos. ${ }^{5}$ Valor isotópico expressos em $\delta^{13} \mathrm{C}$ relativos ao padrão PeeDee Belemnite (PDB). tecido, e assim determinar se o uso dos AFs e Gln/Glu influenciou no desenvolvimento da mucosa intestinal, os pintos de um dia de idade receberam dietas compostas predominantemente por plantas do ciclo $\mathrm{C}_{3}$ (arroz), possuindo sinal isotópico de ${ }^{13} \mathrm{C}$ diferente das dietas $\mathrm{C}_{4}$ fornecida às matrizes $\left(\delta^{13} \mathrm{C}=\sim-28 \% 0\right)$.

Aos $0 ; 0,5 ; 1 ; 1,5 ; 2 ; 2,5 ; 3 ; 3,5 ; 4 ; 4,5 ; 5 ; 7 ; 9 ; 14 ; 21$ foram sacrificadas aleatoriamente três aves por tratamento e colhidas amostras de mucosa do intestino delgado na altura do duodeno por meio de raspagem com lamínula de vidro e acondicionadas em frascos ependorf, identificadas e imediatamente congeladas a $-18^{\circ} \mathrm{C}$ até a sua preparação para as análises isotópicas.

Aos 16 dias de idade, as aves de todos os tratamentos foram inoculadas oralmente e individualmente com 500.000 oocistos de Eimeria acervulina, conforme dose definida por Williams \& Losa (2001) para causar moderadas lesões no epitélio intestinal das aves. Como o ciclo desta espécie de Eimeria é de 4 a 5 dias provocando as primeiras lesões no epitélio intestinal, a partir dos 21 dias de idade, as aves passaram a receber dietas compostas predominantemente por plantas do ciclo $\mathrm{C}_{4}$ (milho), possuindo sinal isotópico de ${ }^{13} \mathrm{C}$ diferentes da dieta na fase inicial $\left(\delta^{13} \mathrm{C} \sim-19 \%\right)$. A mudança na composição da dieta objetiva provocar nova alteração no sinal isotópico do tecido animal para captar a velocidade no turnover da mucosa intestinal após o desafio e, com isso, determinar se o uso dos AFs e Gln/Glu favoreceu a recuperação da mucosa intestinal.

Foram colhidas amostras de mucosa aos 21,$5 ; 22 ; 22,5 ; 23 ; 24$; $25 ; 26 ; 28 ; 35 ; 42$ dias de idade procedendo-se do mesmo modo descrito para a fase anterior.

As análises isotópicas das amostras serão realizadas no Centro de Isótopos Estáveis Ambientais do Instituto de Biociências (CIEA/IBB) da Unesp, Campus de Botucatu. As amostras foram descongeladas e pesadas em cápsulas de estanho, introduzidas no espectrômetro de massa DELTA-S acoplado ao Analisador Elementar e queimadas quantitativamente para obtenção de $\mathrm{CO}_{2} \mathrm{e}$ determinação das razões isotópicas de carbono.

Os resultados foram expressos em notação $\delta^{13} \mathrm{C}$, em relação ao padrão Peedee Belemnite (PDB), com erro de análise da ordem de $0,2 \%$ e calculado pela equação 1 :

$$
\delta{ }^{13} \mathrm{C}_{(\text {amostra, padrão) }}=\left[\left(\mathrm{R}_{\text {amostra }} / \mathrm{R}_{\text {padrão }}\right)-1\right] \times 10^{3}
$$

Onde: $\delta{ }^{13} \mathrm{C}=$ enriquecimento relativo da razão ${ }^{13} \mathrm{C} /{ }^{12} \mathrm{C}$ da amostra em relação ao padrão PDB. Adimensional.; $\mathrm{R}$ = razão isotópica $\left({ }^{13} \mathrm{C} /{ }^{12} \mathrm{C}\right)$ da amostra e do padrão. Adimensional.

Para mensurar quantitativamente a velocidade de substituição do carbono dos tecidos das aves pelos da dieta depois de determinado intervalo de tempo, foi realizado o ajuste exponencial dos dados $\left(\delta^{13} \mathrm{C}_{(\text {amostra, padrão) }}\right)$ utilizando-se o método de equações exponenciais de primeira ordem do software OriginPro ${ }^{\circledR} 8$ Professional (Microcal Software, 2007), expressa pela equação 2 (Ducatti et al., 2002):

$$
\delta^{13} \mathrm{C}(\mathrm{t})=\delta^{13} \mathrm{C}(\mathrm{f})+\left[\delta^{13} \mathrm{C}(\mathrm{i})-\delta^{13} \mathrm{C}(\mathrm{f})\right] \mathrm{e}^{-\mathrm{kt}}
$$

Onde: $\delta^{13} \mathrm{C}(\mathrm{t})=$ enriquecimento isotópico do tecido em qualquer tempo $(\mathrm{t})$. Adimensional; $\delta^{13} \mathrm{C}(\mathrm{f})=$ enriquecimento isotópico do tecido no patamar de equilíbrio, ou condição final. Adimensional.; $\delta^{13} \mathrm{C}(\mathrm{i})=$ enriquecimento isotópico do tecido, na condição inicial. Adimensional.; $\mathrm{k}=$ constante de troca (turnover) em unidades de tempo ${ }^{-1} ; \mathrm{t}=$ tempo (em dias) desde a substituição da ração.

A meia vida $\left(\mathrm{T}_{50 \%}\right)$ do ${ }^{13} \mathrm{C}$ na mucosa intestinal na condição de substituição de $50 \%$ dos átomos de ${ }^{13} \mathrm{C}$ foi mensurada pela equação (3):

$$
\mathrm{T}=\ln 2 / \mathrm{k}
$$


Onde: $\mathrm{T}=$ meia vida em unidade de tempo (dias); $\ln =$ logaritmo niperiano; $\mathrm{k}=$ constante do turnover, unidade: tempo ${ }^{-1}$, fornecendo uma idéia de "velocidade" no processo de troca dos isótopos estáveis nos tecidos (Ducatti et al. 2002).

Para as análises histomorfométricas do intestino delgado, aos 7 e 21 dias de idade, foram colhidos dois segmentos de três centímetros do duodeno, do jejuno e do íleo de duas aves por repetição. Os segmentos foram cortados transversalmente e longitudinalmente, lavados e fixados em solução de formol a $10 \%$ por 24 horas e lavados em água corrente por mais 24 horas. Posteriormente, foram desidratados em uma série crescente de álcoois, diafanizados em xilol e incluídos em Paraplast.

Para as análises histomorfométricas da Bursa de Fabricius, aos $7,14,21,28$ e 35 dias de idade, as mesmas foram colhidas inteiras e fixadas em solução de formol a 10\%. Da mesma maneira que as amostras de intestinos, posteriormente, foram desidratados em série crescente de álcoois, diafanizados em xilol e incluídos em Paraplast.

Com o uso do micrótomo foram obtidos cortes de cinco micrômetros de espessura, os quais foram corados com Hematoxilina e Eosina (Luna 1968) e com microscópio ótico acoplado a sistema analisador de imagens (Leica LAS Interactive Mensurements) e computador, foram medidas a altura das vilosidades e a profundidade das criptas dos segmentos do intestino delgado e a porcentagem do córtex do folículo linfóide bursal. Foram realizadas 20 leituras de altura de vilosidades e profundidade de criptas por segmentos (Loddi 1998). Os folículos bursais, nos quais o corte passou pela região central, foram circundados por uma linha obtendo-se a área folicular total. Em seguida, foi feita a delimitação da porção medular do mesmo folículo, passando uma linha sobre a membrana basal que divide a área cortical da medular para calcular a porcentagem de córtex folicular. As leituras foram realizadas em 10 folículos por amostra (Muniz 2006).

Aos 21, 22, 23, 24, 25, 26, 28 e 35 dias de idade foram avaliados os escores de lesão do epitélio intestinal de acordo com a metodologia de Johnson \& Reid (1970) e com 4, 5, 6 e 7 dias após a inoculação, foram coletadas fezes para contagem de oocistos. As fezes foram coletadas de cada unidade experimental, homogeneizadas e uma amostra de duas gramas foi diluída em $60 \mathrm{~mL}$ de solução saturada de $\mathrm{NaCl}$. A contagem foi realizada em câmara de MacMaster e expressa em número de oocistos por grama de fezes (Hodgson 1970).

Os dados foram tabulados e analisados com auxílio do procedimento GLM do software SPSS 13.0 for Windows (2004) e as médias foram comparadas pelo teste de Tukey a $5 \%$ de probabilidade.

\section{RESULTADOS E DISCUSSÃO}

\section{Escores de lesão do epitélio intestinal e contagem de oocistos}

Não houve efeito dos tratamentos para escore de lesão (Quadro 2). Com a dosagem utilizada, era esperado observar moderadas lesões no epitélio intestinal. Porém, entre 5 e 7 dias após inoculação, foram observadas lesões mais severas com escores muito altos, indicando que os oocistos inoculados possuíam alta patogenicidade. 0 elevado grau das lesões dificultou a observação dos possíveis efeitos dos tratamentos.

Em aves criadas em gaiolas, a reinfestação por oocistos liberados nas fezes é menos evidente, permitindo a recuperação da mucosa intestinal, o que, neste estudo, ocorreu a partir dos 26 dias de idade. Foi possível verificar que após 5 dias do aparecimento das primeiras lesões, as aves dos tratamentos com Gln/Glu não apresentavam mais lesões indicando rápida recuperação da mucosa intestinal, o que pode estar associado ao fato da glutamina e ácido glutâmico contribuírem com o fornecimento de energia necessário para células que proliferam rapidamente, como as células do intestino, além de serem considerados como precursores para síntese de outros aminoácidos e nucleotídeos importantes na síntese protéica (Newsholme 2003a, 2003b).

Houve efeito dos tratamentos $(\mathrm{P}<0,05)$ para número de oocistos excretados por grama de fezes aos 4 e 5 dias após inoculação e no período total de coleta (Quadro 3).

Após 4 dias, o menor número de oocistos excretados foi observado no grupo de aves alimentadas com dieta contendo AMD/AC, AFs e Gln/Glu + AFs em relação ao grupo alimentado com DC, DC + Vacina e os alimentados com dieta contendo Gln/Glu, sendo que frangos do grupo recebendo DC + Vacina e Gln/Glu excretaram menor número de oocistos que os do grupo controle. Após 5 dias, o menor valor encontrado foi no tratamento contendo AFs, seguido do tratamento contendo Gln/Glu + AFs. Os maiores valores ocorreram para frangos do grupo controle e os alimentados com dieta suplementada com Gln/Glu em relação aos do grupo tratado com AFs, não diferindo dos alimentados com AMD/AC e DC+Vacina. Para a quantidade total de oocistos excretados no período acumulado de 4 a 7 dias, os menores valores foram observados para os

Quadro 2. Escores de lesão no intestino dos frangos, segundo os tratamentos, aos 5, 6, 7, 8, 9, 10, 12 e 19 dias após inoculação com Eimeria acervulina $(21,22,23,24,25$, 26,28 e 35 dias de idade)

\begin{tabular}{lcccccccc}
\hline Tratamentos & $\begin{array}{c}5 \mathrm{~d} \\
(21)\end{array}$ & $\begin{array}{c}6 \mathrm{~d} \\
(22)\end{array}$ & $\begin{array}{c}7 \mathrm{~d} \\
(23)\end{array}$ & $\begin{array}{c}8 \mathrm{~d} \\
(24)\end{array}$ & $\begin{array}{c}9 \mathrm{~d} \\
(25)\end{array}$ & $\begin{array}{c}10 \mathrm{~d} \\
(26)\end{array}$ & $\begin{array}{c}12 \mathrm{~d} \\
(28)\end{array}$ & $\begin{array}{c}19 \mathrm{~d} \\
(35)\end{array}$ \\
\hline DC $^{1}$ & 4,00 & 3,67 & 3,67 & 3,67 & 1,33 & 0,33 & 0,33 & 0,00 \\
DC+Vacina $^{2}$ & 3,67 & 3,00 & 2,67 & 1,67 & 0,33 & 0,33 & 0,00 & 0,00 \\
${\text { AMD } / \mathrm{AC}^{3}}^{3}$ & 3,33 & 3,33 & 2,33 & 2,33 & 0,33 & 0,33 & 0,33 & 0,00 \\
Gln/Glu $^{4}$ & 4,00 & 4,00 & 3,67 & 1,00 & 0,00 & 0,00 & 0,00 & 0,00 \\
AFs $^{5}$ & 3,67 & 3,33 & 3,67 & 2,00 & 0,67 & 0,33 & 0,33 & 0,00 \\
Gln/Glu+AFs $^{2}$ & 3,67 & 3,00 & 3,00 & 2,00 & 0,33 & 0,00 & 0,00 & 0,00 \\
CV (\%) & 4,00 & 3,67 & 3,67 & 3,67 & 1,33 & 0,33 & 0,33 & 0,00 \\
P & 0,538 & 0,758 & 0,214 & 0,058 & 0,353 & 0,948 & 0,909 & 1,000
\end{tabular}

${ }^{1}$ Dieta controle isenta de aditivos (DC); ${ }^{2}$ DC mais vacina contra coccidiose no $3^{\text {o }}$ dia de idade; ${ }^{3}$ Dieta com adição de antibiótico (Surmax ${ }^{\circledR}$ ) e anticoccidiano (Monempac ${ }^{\circledR}$ ); ${ }^{4}$ DC mais glutamina e ácido glutâmico; ${ }^{5}$ DC mais aditivos fitogênicos.

Quadro 3. Número de oocistos de Eimeria acervulina por grama de fezes, segundo os tratamentos, aos 4, 5, 6 e 7 dias após inoculação nas aves.

\begin{tabular}{|c|c|c|c|c|c|c|c|c|}
\hline & $\mathrm{DC}^{1}$ & $\begin{array}{c}\text { DC+ } \\
\text { Vacina }^{2}\end{array}$ & $\begin{array}{c}\mathrm{AMD} / \\
\mathrm{AC}^{3}\end{array}$ & $\begin{array}{l}\text { Gln/ } \\
\text { Glu }^{4}\end{array}$ & $\mathrm{AFs}^{5}$ & $\begin{array}{c}\mathrm{Gln} / \\
\mathrm{Glu}+\mathrm{AFs}\end{array}$ & $\begin{array}{l}\text { CV } \\
(\%)\end{array}$ & $\mathrm{P}$ \\
\hline & & \multicolumn{7}{|c|}{ Oocistos por grama de fezes (x1000) } \\
\hline & $667^{c}$ & $297^{b}$ & $263^{\mathrm{a}}$ & $541^{\mathrm{bc}}$ & $204^{\mathrm{a}}$ & $253^{\mathrm{a}}$ & 26,27 & 0,001 \\
\hline 5 dias & $2.167^{c}$ & $1.883^{\mathrm{bc}}$ & $1.867^{\mathrm{bc}}$ & $2.038^{\mathrm{c}}$ & $1.027^{\mathrm{a}}$ & $1.173^{\mathrm{ab}}$ & 16,23 & 0,003 \\
\hline 6 dias & 91 & 76 & 47 & 68 & 80 & 90 & 26,80 & 0,154 \\
\hline $7 \mathrm{di}$ & 19 & 10 & 9 & 14 & 19 & 9 & 32,55 & 0,054 \\
\hline Soma & $2.944^{b}$ & $2.266^{\mathrm{ab}}$ & $2.186^{\mathrm{ab}}$ & $2.661^{b}$ & $1.330^{\mathrm{a}}$ & $1.525^{\mathrm{a}}$ & 16,88 & 0,002 \\
\hline
\end{tabular}

${ }^{1}$ Dieta controle isenta de aditivos (DC); ${ }^{2}$ DC mais vacina contra coccidiose no $3^{\circ}$ dia de idade; ${ }^{3}$ Dieta com adição de antibiótico (Surmax ${ }^{\circledR}$ ) e anticoccidiano (Monempac ${ }^{\circledR}$ ); ${ }^{4}$ DC mais glutamina e ácido glutâmico; ${ }^{5}$ DC mais aditivos fitogênicos. Médias seguidas de letras diferentes na mesma linha diferem estatisticamente entre si pelo teste de Tukey $(\mathrm{P}<0,05)$. 
dois tratamentos contendo AFs em relação ao tratamento controle e Gln/Glu, não diferindo dos tratamentos AMD/ AC e DC+Vacina.

Um dos principais efeitos fisiológicos dos diferentes AFs que tem sido relatado em aves é a sua ação antibacteriana e anticoccidiana. Frente ao desafio com coccidiose, alguns pesquisadores relataram diminuição na contagem de oocistos e escores de lesão no epitélio intestinal de aves alimentadas com dieta suplementada com AFs em relação à aves alimentadas com dieta sem suplementação (Evans et al. 2001, Giannenas et al. 2003, Christaki et al. 2004, Yi et al. 2005), inclusive em relação às aves alimentadas com dieta contendo antibiótico melhorador de desempenho e anticoccidianos (Miguel et al. 2009). Neste estudo, o menor número de oocistos excretados nas fezes foi observado nos tratamentos contendo AFs seguidos do contendo AMD/AC, confirmando os efeitos benéficos dos AFs no controle da coccidiose.

\section{Histomorfometria da mucosa intestinal}

Os resultados das análises histomorfométricas do intestino delgado aos sete dias de idade estão apresentados na Quadro 4. Houve influência dos tratamentos $(\mathrm{P}<0,05)$ apenas para altura de vilosidade e profundidade de criptas dos segmentos do duodeno e íleo. A maior altura de vilosidade no duodeno foi observada no tratamento Gln/Glu em relação ao DC, DC + Vacina e AFs, não deferindo dos tratamentos Gln/Glu + AFs e AMD/AC, que não diferiram entre si nem dos demais tratamentos. A maior profundidade de cripta no duodeno foi observada nos tratamentos Gln/Glu e DC + Vacina em relação ao DC, não diferindo dos demais tratamentos, que não diferiram do $\mathrm{DC}$ e nem entre si. A maior altura de vilosidade no íleo foi observada no tratamento Gln/Glu em relação ao DC, não deferindo dos demais tratamentos, que também não diferiram entre si e nem do DC. A maior profundidade de cripta do íleo foi observada nos tratamentos Gln/Glu e Gln/Glu + AFs em relação aos demais tratamentos que não diferiram entre si.

Os resultados das análises histomorfométricas do intestino delgado aos 21 dias de idade estão apresentados na Quadro 5. Houve influência dos tratamentos $(\mathrm{P}<0,05)$ apenas para altura de vilosidade e profundidade de criptas dos segmentos do duodeno e íleo. Aves do tratamento Gln/Glu e Gln/Glu + AFs apresentaram maior altura de vilosidades do duodeno em relação às aves do tratamento controle, não diferindo dos demais tratamentos que não diferiram entre si. Maior profundidade das criptas do duodeno foi encontrada para o tratamento Gln/Glu em relação ao DC e DC + Vacina, não diferindo de AFs e Gln/Glu + AFs e AMD/AC. Aves do tratamento Gln/Glu, AFs e Gln/Glu + AFs apresentaram maior altura de vilosidades do íleo em relação às aves do tratamento DC e AMD/AC. As aves do tratamento DC + Vacina apresentaram menor altura de vilosidades em relação ao tratamento Gln/Glu + AFs, não diferindo dos demais tratamentos. Maior profundidade das criptas do íleo foi observada para aves do tratamento Gln/Glu + AFs em relação ao controle, DC + Vacina e AMD/AC não diferindo de Gln/Glu e AFs.

A glutamina e ácido glutâmico, além de contribuírem com o fornecimento de energia necessário para o desempenho das atividades metabólicas de células que proliferam rapidamente, como as células do sistema imune e intestino (Newsholme 2003a, 2003b), também são considerados precursores para síntese de purinas e pirimidinas, constituintes básicos dos nucleotídeos, componentes das moléculas de DNA e RNA e de outros aminoácidos, suportando a divisão (turnover) das células da cripta, resultando no aumento do número e altura dos vilos e auxiliando no reparo das injúrias no epitélio intestinal (Piva et al. 2001). Outra importante função da glutamina é a indução mecanismos de transcrição gênica pela ativação da proteína quinase, que é uma enzima que ativa mitogênese na região das criptas do epitélio intestinal, levando ao aumento da proliferação celular, influenciando na manutenção da estrutura da mucosa (Blikslager \& Roberts 1997, Rhoads et al. 1997). Já os aditivos fitogênicos vêm sendo estudados como suplementos eficazes na redução de infecções tanto por bactérias quanto por Eimerias sp. (Evans et al. 2001, Giannenas et al. 2003, Christaki et al. 2004, Jamroz et al. 2005, Miguel et al. 2009, Vasconcelos et al. 2010).

Neste estudo, aos sete dias de idade foi possível verificar a ação da glutamina e ácido glutâmico nos segmentos do duodeno e íleo com aumento significativo na altura das vilosidades e profundidade das criptas (Quadro 4), corroborando os de outros autores que também verificaram efeitos benéficos da glutamina sobre o desenvolvimento da mucosa intestinal na primeira semana de vida de aves alimentadas com dieta suplementada com glutamina (Maiorka et al. 2000, Sakamoto et al. 2005, Bartell \& Batal 2007, Murakami et al. 2007), aumentando a capacidade funcional da mesma, o que pode propiciar melhor desempenho das aves por meio da maior capacidade de digerir e absorver os nutrientes da dieta. Quanto à maior profundidade de criptas na região do duodeno para o tratamento DC + Vacina nesta fase de criação, este pode ter ocorrido em função da vacina contra coccidiose, aumentando a proliferação das células da cripta na tentativa de reparar os possíveis danos causados pela vacina nas vilosidades intestinais.

Aos 21 dias de idade, 5 dias após inoculação com oocistos de Eimeria acervulina, o epitélio intestinal das aves, em

\begin{tabular}{|c|c|c|c|c|c|c|c|c|}
\hline \multicolumn{9}{|c|}{$\begin{array}{l}\text { Quadro 4. Valores médios de altura de vilos (AV) e profundidade } \\
\text { de criptas (PC) do duodeno, jejuno e ileo de frangos de corte, } \\
\text { segundo os tratamentos, aos sete dias de idade }\end{array}$} \\
\hline \multirow[t]{2}{*}{ Variáveis } & \multicolumn{6}{|c|}{ Tratamentos } & \multirow{2}{*}{$\begin{array}{l}\mathrm{CV} \\
(\%)\end{array}$} & \multirow[t]{2}{*}{$\mathrm{P}$} \\
\hline & $\mathrm{DC}^{1}$ & $\begin{array}{c}\text { DC+ } \\
\text { Vacina }^{2}\end{array}$ & $\begin{array}{l}\mathrm{AMD} / \\
\mathrm{AC}^{3}\end{array}$ & $\begin{array}{l}\text { Gln/ } \\
\mathrm{Glu}^{4}\end{array}$ & $\mathrm{AFs}^{5}$ & $\begin{array}{c}\text { Gln/ } \\
\text { Glu+AFs }\end{array}$ & & \\
\hline
\end{tabular}
Duodeno

$\mathrm{AV}(\mu \mathrm{m}) 738,79^{\mathrm{b}} 763,30^{\mathrm{b}} 829,54^{\text {ab }} 974,64^{\mathrm{a}} 788,60^{\mathrm{b}} 803,48^{\text {ab }} 7,95 \quad 0,008$ PC $(\mu \mathrm{m}) 108,84^{\mathrm{b}} 127,98^{\mathrm{a}} 116,86^{\text {ab }} 125,53^{\mathrm{a}} 115,91^{\text {ab }} 124,47^{\text {ab }} 5,05 \quad 0,075$ Jejuno

$\mathrm{AV}(\mu \mathrm{m}) \quad 469,50 \quad 447,03 \quad 485,19 \quad 486,77 \quad 498,73 \quad 475,74 \quad 12,14 \quad 0,044$

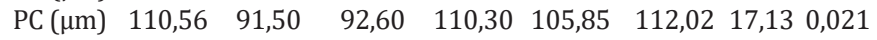
Íleo

AV $(\mu \mathrm{m}) 300,22^{\mathrm{b}} 324,28^{\mathrm{ab}} 316,55^{\text {ab }} 423,27^{\mathrm{a}} 332,20^{\mathrm{ab}} 397,75^{\mathrm{ab}} 12,570,719$ PC $(\mu \mathrm{m}) \quad 73,51^{\mathrm{b}} \quad 74,28^{\mathrm{b}} \quad 70,09^{\mathrm{b}} \quad 115,99^{\mathrm{a}} \quad 73,53^{\mathrm{b}} \quad 106,66^{\mathrm{a}} \quad 13,04 \quad 0,003$

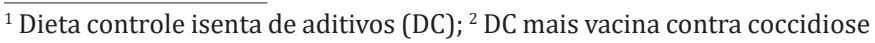
no $3^{\circ}$ dia de idade; ${ }^{3}$ Dieta com adição de antibiótico $\left(\right.$ Surmax $\left.^{\circledR}\right)$ e anticoccidiano (Monempac ${ }^{\circledR}$ ); ${ }^{4}$ DC mais glutamina e ácido glutâmico; ${ }^{5}$ DC mais aditivos fitogênicos. Médias seguidas de letras diferentes na mesma linha diferem estatisticamente entre si pelo teste de Tukey $(\mathrm{P}<0,05)$. 
todos os tratamentos, já se apresentava lesado. Observa-se que as vilosidades intestinais do duodeno das aves, nesta idade, apresentam altura bem inferior às vilosidades do duodeno das aves aos sete dias de idade, comprovando a destruição causada pelos oocistos. Os melhores resultados para altura de vilosidade e profundidade de criptas do duodeno e do íleo, nesta fase, foram observados nas aves alimentadas com dieta suplementada com Gln/Glu e AFs (Quadro 5), possivelmente pelo fornecimento de energia e contribuição para síntese de nucleotídeos e outros aminoácidos pela Glu/Glu e, diminuição da destruição das células epiteliais pela ação anticoccidiana e antibacteriana dos AFs. Em estudo conduzido por Nascimento et al. (2014), também foi observado influência da glutamina suplementada à dieta sobre as estruturas do intestino delgado de frangos de corte, com aumento significativo da profundidade das criptas do duodeno, jejuno e íleo aos 18 e 42 dias de idade, concluindo que este aminoácido pode melhorar o desenvolvimento da mucosa intestinal. Por outro lado, Shakeri et al. (2014), suplementando dieta de frangos de corte com glutamina e ácido glutâmico, com o objetivo de avaliar seus efeitos em aves alojadas em maior densidade, observaram

Quadro 5. Valores médios de altura de vilos (AV) e profundidade de criptas (PC) do duodeno, jejuno e íleo de frangos de corte, segundo os tratamentos, 5 dias após inoculação das aves com oocistos de Eimeria acervulina (21 dias de idade)

\begin{tabular}{|c|c|c|c|c|c|c|c|c|}
\hline \multirow[t]{2}{*}{ Variáveis } & \multicolumn{6}{|c|}{ Tratamentos } & \multirow{2}{*}{$\begin{array}{l}\text { CV } \\
\text { (\%) }\end{array}$} & $\mathrm{P}$ \\
\hline & $\mathrm{DC}^{1}$ & $\begin{array}{c}\text { DC+ } \\
\text { Vacina }^{2}\end{array}$ & $\begin{array}{c}\mathrm{AMD} / \\
\mathrm{AC}^{3}\end{array}$ & $\begin{array}{l}\text { Gln/ } \\
\mathrm{Glu}^{4}\end{array}$ & $\mathrm{AFs}^{5}$ & $\begin{array}{c}\text { Gln/ } \\
\text { Glu+AFs }\end{array}$ & & \\
\hline
\end{tabular}

Duodeno

AV $(\mu \mathrm{m}) 404,45^{\mathrm{b}} 454,02^{\text {ab }} 471,39^{\text {ab }} 614,55^{\text {a }} 462,81^{\text {ab }} 578,65^{\text {a }} 13,000,018$ PC $(\mu \mathrm{m}) 388,92^{\text {b }} 365,69^{\mathrm{b}} 416,86^{\text {ab }} 517,66^{\mathrm{a}} 428,80^{\text {ab }} 475,79^{\text {ab }} 10,570,631$ Jejuno

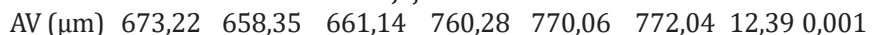

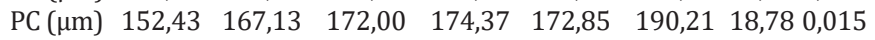
Íleo

$\mathrm{AV}(\mu \mathrm{m}) 482,24^{\mathrm{c}} 506,36^{\text {bc }} 449,84^{\mathrm{c}} 593,71^{\text {ab }} 584,85^{\text {ab }} 599,63^{\text {a }} \quad 6,190,707$ PC $(\mu \mathrm{m}) 116,21^{\mathrm{b}} 113,95^{\mathrm{b}} 110,45^{\mathrm{b}} 150,72^{\text {ab }} 118,40^{\text {ab }} 161,31^{\text {a }} 13,040,027$

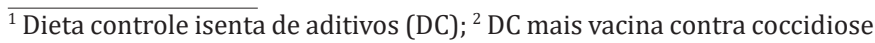
no $3^{\text {o }}$ dia de idade; ${ }^{3}$ Dieta com adição de antibiótico $\left(\right.$ Surmax $\left.^{\circledR}\right)$ e anticoccidiano (Monempac ${ }^{\circledR}$ ); ${ }^{4}$ DC mais glutamina e ácido glutâmico; ${ }^{5}$ DC mais aditivos fitogênicos. Médias seguidas de letras diferentes na mesma linha diferem estatisticamente entre si pelo teste de Tukey $(\mathrm{P}<0,05)$.

Quadro 6. Porcentagem da região cortical da Bursa de fabrícius de frangos de corte segundo os tratamentos aos $7,14,21,28$ e 35 dias de idade

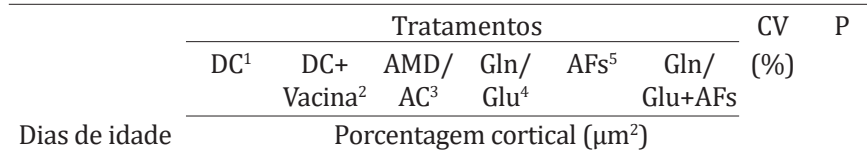

7 dias $\quad 36,66^{\mathrm{c}} \quad 40,17^{\mathrm{bc}} 41,40^{\mathrm{bc}} 47,80^{\mathrm{a}} 44,13^{\text {ab }} \quad 45,39^{\mathrm{ab}} \quad 5,240,001$

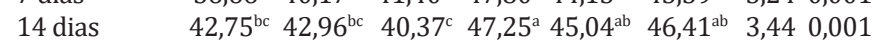

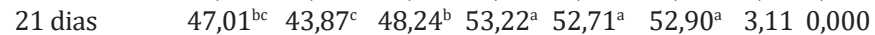

$\begin{array}{lllllllll}28 \text { dias } & 48,74 & 49,33 & 51,04 & 51,96 & 50,60 & 50,63 & 7,43 & 0,889\end{array}$

35 dias $\quad \begin{array}{llllllll}50,37 & 51,44 & 49,30 & 51,63 & 50,37 & 51,46 & 6,87 & 0,958\end{array}$

${ }^{1}$ Dieta controle isenta de aditivos (DC); ${ }^{2}$ DC mais vacina contra coccidiose no $3^{\circ}$ dia de idade; ${ }^{3}$ Dieta com adição de antibiótico (Surmax ${ }^{\circledR}$ ) e anticoccidiano (Monempac ${ }^{\circledR}$ ); ${ }^{4}$ DC mais glutamina e ácido glutâmico; ${ }^{5}$ DC mais aditivos fitogênicos. Médias seguidas de letras diferentes na mesma linha diferem estatisticamente entre si pelo teste de Tukey $(\mathrm{P}<0,05)$. efeito benéfico sobre a viabilidade, porém nenhum efeito benéfico no desempenho ou morfologia intestinal das aves. Outros pesquisadores também relataram melhores alturas de vilosidades e menores efeitos deletérios sobre as células da mucosa intestinal de frangos de corte quando alimentados com dieta suplementada com glutamina (Yi et al. 2005, Lopes 2008), ou aditivos fitogênicos (Miguel et al. 2009), frente ao desafio com coccidiose. Para Wilmore \& Shabert (1998) e Souba et al. (1990), a suplementação com glutamina pode ser benéfica para manutenção do metabolismo e apoio terapêutico da mucosa intestinal e sistema imunológico especialmente em condições de doenças ou traumas, quando a barreira da mucosa intestinal pode ficar comprometida. Os resultados deste experimento sugerem o efeito benéfico da glutamina e do ácido glutâmico no desenvolvimento, na manutenção e reparo das injúrias do epitélio intestinal causados pela coccidiose, bem como dos aditivos fitogênicos no controle da doença.

\section{Histomorfometria da Bursa de Fabricius}

Os resultados das análises histomorfométricas da Bursa de Fabricius estão apresentados na quadro 6. Aos 7 dias de idade, as maiores porcentagens de área cortical do folículo bursal $(\mathrm{P}<0,05)$ foram observadas nas aves do tratamento Gln/Glu, AFs e Gln/Glu+AFs em relação ao controle. Estes dois últimos não diferiram dos tratamentos DC+Vacina e $\mathrm{AMD} / \mathrm{AC}$ que não diferiram do controle.

Aos 14 dias de idade, as maiores porcentagens de área cortical $(\mathrm{P}<0,05)$ foram observadas nas aves dos tratamentos Gln/Glu, AFs e Gln/Glu +AFs em relação ao AMD/AC. Estes dois últimos não diferiram do DC e DC + Vacina que não diferiram do AMD/AC. Aos 21 dias de idade, as maiores porcentagens de área cortical do folículo bursal $(\mathrm{P}<0,05)$ foram observadas nas aves do tratamento Gln/Glu, AFs e Gln/Glu + AFs em relação ao DC, DC + Vacina e AMD/AC. As aves do tratamento DC + Vacina apresentaram a menor $(\mathrm{P}<0,05)$ porcentagem de área cortical não diferindo apenas do controle. Não houve influência dos tratamentos aos 28 e 35 dias de idade.

A glutamina é muito utilizada em altas taxas por células isoladas do sistema imune, como linfócitos, macrófagos e neutrófilos (Newsholme et al. 1985, Newsholme 2001, Newsholme et al. 2003a, 2003b). Segundo Newsholme (2001), o fato de o nitrogênio amínico da glutamina ser utilizado para síntese de nucleotídeos, seria um dos fatores que explica a alta necessidade de glutamina em células que se proliferam rapidamente, como as do sistema imune e da mucosa intestinal. Glutamina e ácido glutâmico também têm sido reconhecidos como importante substrato energético (Reeds \& Burrin 2001, Newsholme et al. 2003a, 2003b) contribuindo de forma substancial para o fornecimento de energia necessária para o desempenho das atividades metabólicas destas células. Segundo Yaqoob \& Calder (1997), proliferação de linfócitos T não ocorre na ausência de glutamina e, com o aumento da concentração de glutamina, aumenta proliferação de linfócitos, o que os tornam dependentes de glutamina. A diferenciação de linfócitos B e síntese de anticorpos também é dependente de glutamina, segundo Crawford \& Cohen (1985). 
Estudos em animais indicam que as concentrações plasmáticas de glutamina estão diminuídas em situações de estresse, como infecções (Ardawi \& Majzoub 1991) e ferimentos (Albina et al. 1987) e, diante dos efeitos estimuladores da glutamina já relatados, parece ser importante fornecer glutamina para animais nestas situações para o bom funcionamento do sistema imunológico.

Aditivos fitogênicos também vêm sendo relatados como potente imunoestimulador (Awaad et al. 2010). Estes autores observaram maior concentração de anticorpos e peso relativo da Bursa de Fabricius em frangos de corte vacinados contra influenza aviária quando alimentados com aditivos fitogênicos (óleos essenciais de eucalipto e menta) em relação ao grupo alimentado com dieta não suplementada.

A bursa é constituída de folículos linfóides os quais são subdivididos em região medular e região cortical. A região medular é formada principalmente por linfoblástos; já o córtex folicular é composto, em sua maior parte, por lifócitos (Hodges 1974), sendo nesta região o local onde ocorre a maior parte da diferenciação e maturação de linfócitos B, responsáveis pela produção de anticorpos (Warner \& Szenberg 1964).

Neste estudo observamos o efeito benéfico da Gln/Glu e dos AFs sobre o desenvolvimento da Bursa de Fabricius, propiciando maior porcentagem de área cortical aos 7, 14 e 21 dias de idade. Aumento da área cortical também foi observado por Fascina et al. (2011) em frangos suplementados com os mesmos aditivos fitogênicos deste estudo. Como a região cortical é o local onde ocorre a maior parte da diferenciação e maturação de linfócitos B, podemos presumir que a maior porcentagem de área cortical implica em melhores condições para resposta imune frente à desafios infecciosos.

Após a eclosão dos pintos, a bursa cresce e se desenvolve rapidamente durante as três primeiras semanas; a partir daí, segundo Glick (1957), começa a sofrer um processo gradual de involução. Neste estudo não observamos esse processo de involução a partir desta fase, nem o efeito dos aditivos utilizados.

\section{Turnover da mucosa intestinal}

Os resultados da taxa de turnover da mucosa intestinal dos frangos na fase de 1 a 21 dias de idade encontram-se mostrados nas Figuras de 1A e B. As análises dos resultados de $\delta^{13} \mathrm{C}$ da mucosa intestinal das aves resultaram nas meias-vidas de 1,23 dias; 1,21 dias; 1,22 dias; 1,20 dias; 1,19 dias e 1,19 dias para as aves dos tratamentos Controle, Controle + Vacina, AMD/AC, Gln/Glu, AFs, AFs + Gln/Glu, respectivamente.

Verifica-se nesta fase que os valores de meia vida da mucosa intestinal das aves dos tratamentos com Gln/Glu ( $\mathrm{T}=1,20$ dias), $\mathrm{AFs}$ ( $\mathrm{T}=1,19$ dias) e Gln/Glu + AFs ( $\mathrm{T}=1,19$ dias), foram menores quando comparados com os do tratamento controle ( $\mathrm{T}=1,25$ dias) e AMD/AC ( $\mathrm{T}=1,22$ dias), indicando que a suplementação com Gln/Glu e AFs propicia aceleração na velocidade de troca do carbono na mucosa intestinal de frangos de corte na fase inicial de crescimento, representando maior taxa de turnover deste tecido e, portanto, maior aceleração no crescimento intestinal. Esses resultados evidenciam o efeito trófico destes nutrientes sobre o epitélio intestinal, estimulando o aumento da taxa de proliferação celular.
Muitos agentes tróficos são indutores de mecanismos de transcrição gênica pela ativação de enzimas importantes no processo mitótico na região das críptas, como por exemplo, a ativação da proteína quinase, que é uma enzima que ativa mitogênese e que ocorre quando da presença de Gln (Blikslager \& Roberts 1997). Outros têm ação indireta, ou seja, favorecem os mecanismos de manutenção da integridade epitelial por permitir maior sanidade na mucosa intestinal (Maiorka et al. 2002) e que parece ser o caso dos AFs. Mais outro efeito da Gln e Glu sobre a constituição da mucosa intestinal se deve ao fato de serem substratos energéticos para os enterócitos e fornecerem nitrogênio para síntese de nucleotídeos (Reeds \& Burrin 2001, Newsholme et al. 2003a, 2003b) importantes para tecidos de rápido turnover celular como, no caso, a mucosa intestinal. A meia vida encontrada para o tratamento Controle + Vacina ( $\mathrm{T}=1,21$ dias de idade), menor que do tratamento controle e AMD/AC, pode ter ocorrido em função da vacina contra coccidiose, aumentando a proliferação celular na tentativa de reparar os possíveis danos nas vilosidades, consequentemente, acelerando a troca tecidual.

Os resultados da taxa de turnover da mucosa intestinal dos frangos na fase de 21 a 42 dias de idade (após desafio com Eimeria acervulina) encontram-se nas Figuras 2A,B.
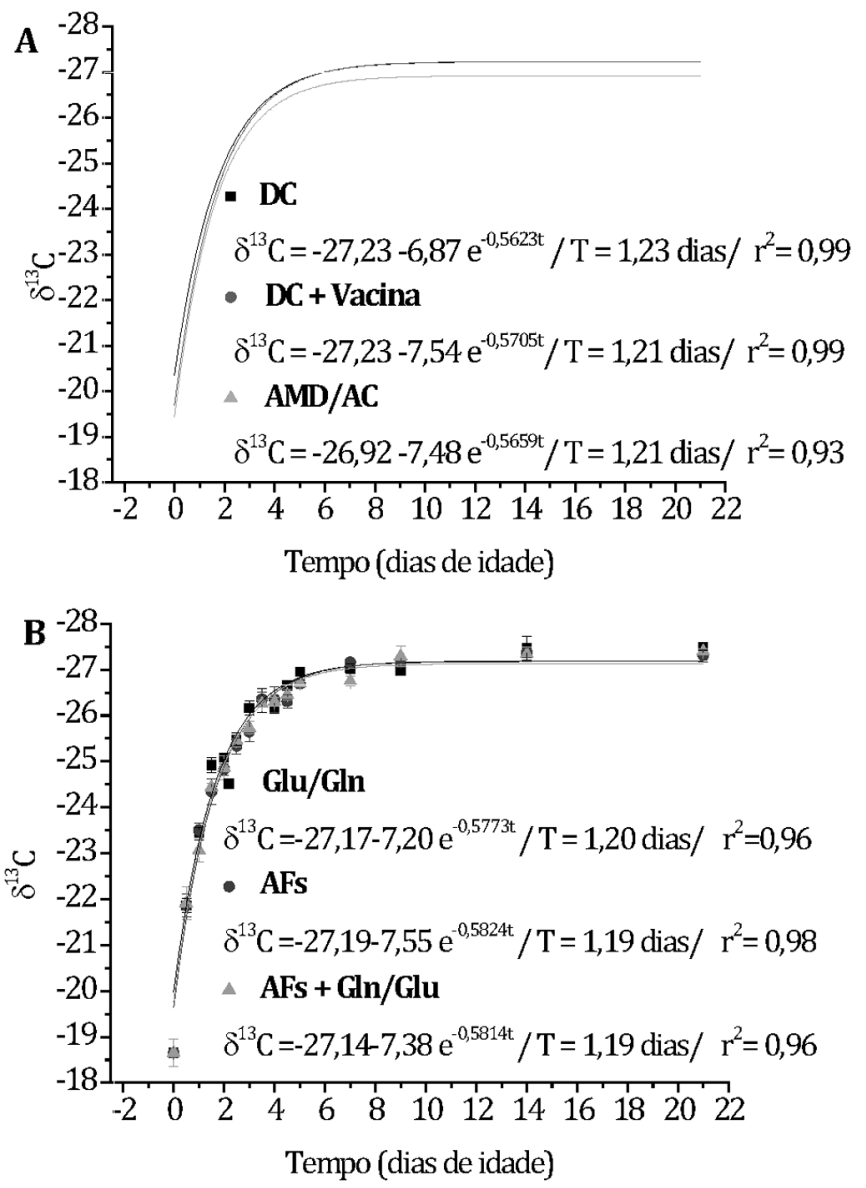

Fig.1. (A,B) Modelo exponencial do turnover dos isótopos estáveis do ${ }^{13} \mathrm{C}$ da mucosa intestinal de frangos de 1-21 dias de idade e valores de meia vida (T), em dias e seus respectivos coeficientes de determinação $\left(\mathrm{r}^{2}\right)$. 

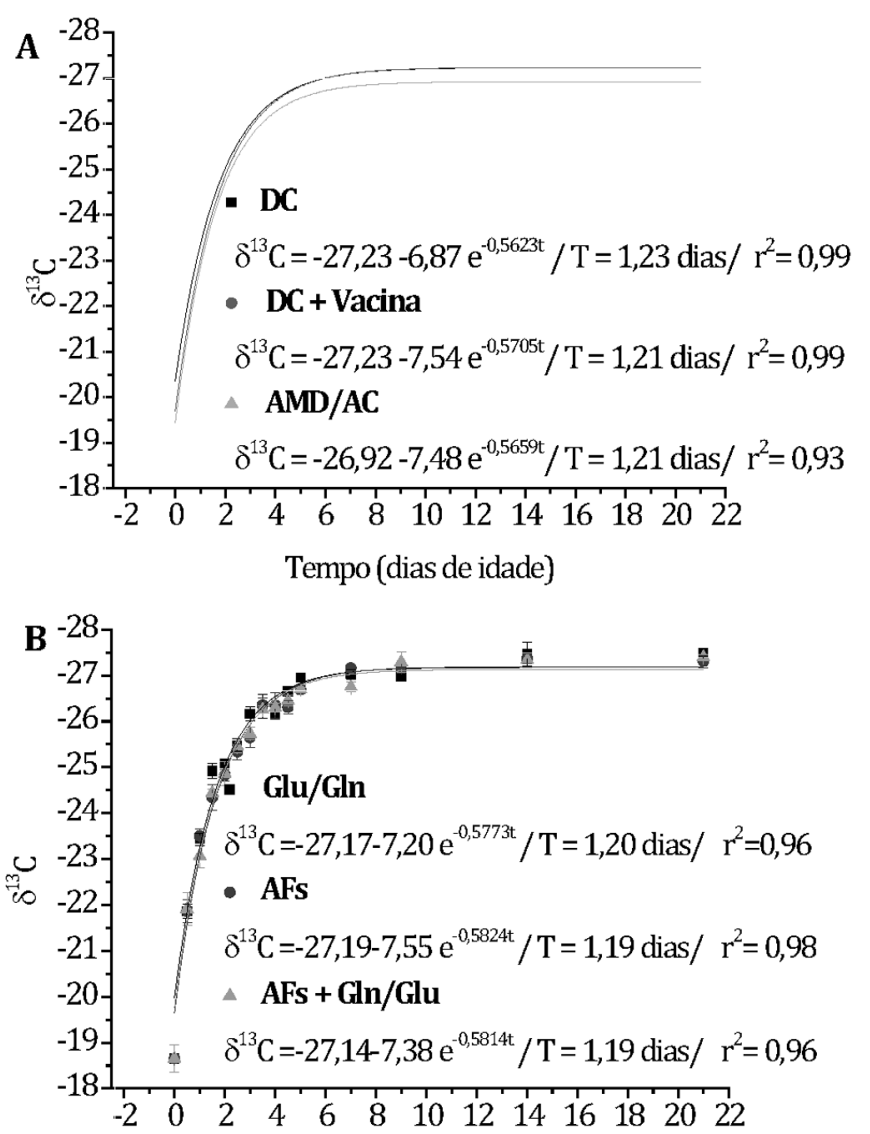

Fig.2. (A,B) Modelo exponencial do turnover dos isótopos estáveis do ${ }^{13} \mathrm{C}$ da mucosa intestinal de frangos de 21-42 dias de idade e valores de meia vida (T), em dias e seus respectivos coeficientes de determinação $\left(\mathrm{r}^{2}\right)$.

As análises dos resultados de $\delta^{13} \mathrm{C}$ da mucosa intestinal das aves resultaram nas meias-vidas de 0,85 dias; 0,84 dias; 1,14 dias; 0,72 dias; 1,15 dias e 1,01 dias para as aves dos tratamentos Controle, Controle + Vacina, AMD/AC, Gln/Glu, $\mathrm{AFs}, \mathrm{AFs}+\mathrm{Gln} / \mathrm{Glu}$, respectivamente.

Verifica-se nesta fase que os valores de meia vida ( $\mathrm{T}$ ) dos tratamentos Controle $(\mathrm{T}=0,85$ dias), Controle + Vacina ( $\mathrm{T}=0,84$ dias) e com $\mathrm{Gln} / \mathrm{Glu}$ ( $\mathrm{T}=0,72$ dias) foram menores quando comparados com os dos demais tratamentos. As aves destes três tratamentos apresentaram pouca mucosa no momento da coleta, sugerindo que esses grupos tiveram grande parte da mucosa intestinal destruída pelos coccídeos aumentando a proporção de tecido novo recém formado em relação ao pré-existente. Isto já era esperado, uma vez que estes tratamentos não possuem aditivos com função coccidiostática. Dentre esses três grupos, o menor valor de T ocorreu no tratamento com Gln/Glu, indicando maior velocidade na substituição do carbono da mucosa, representando maior taxa de turnover deste tecido. Isso deve ter ocorrido devido ao maior aporte energético e de substratos disponíveis para o sistema celular da mucosa (Reeds \& Burrin 2001, Newsholme et al. 2003a, 2003b), uma vez que em momentos de desafio, a síntese endógena de Gln e Glu não é suficiente para atender as necessidades deste tecido (Young \& Marchini 1990). Em estudo com leitões, de- senvolvido por Caldara et al. (2010), a glutamina também acelerou o turnover da mucosa intestinal, evidenciando a ação benéfica da glutamina na recuperação da estrutura do intestino após o desafio causado pelo desmame.

Os maiores valores de $\mathrm{T}$ foram encontrados nos tratamentos com AMD/AC ( $\mathrm{T}=1,14$ dias), AFs ( $\mathrm{T}=1,14$ dias) e com $\mathrm{Gln} / \mathrm{Glu}+\mathrm{AFs}$ ( $\mathrm{T}=1,01$ dias). Esses resultados sugerem que AMD/AC e AFs foram capazes de controlar, em parte, a coccidiose diminuindo a destruição celular, o que implica em menor velocidade de troca deste tecido em relação aos dos demais tratamentos.

A ação coccidiostática dos AFs já foi observada em outros estudos (Christaki et al. 2004, Evans et al. 2001, Giannenas et al. 2003, Miguel et al. 2009). Dentre esses três grupos o menor valor de T foi o encontrado no tratamento com Gln/Glu + AFs, mostrando, mais uma vez, que Gln e Glu influenciam no processo de renovação da mucosa intestinal, acelerando sua regeneração após os danos causados por patógenos.

\section{CONCLUSÕES}

Glutamina mais ácido glutâmico e aditivos fitogênicos oferecem melhorias à estrutura e, consequentemente, à função do intestino, bem como melhores condições para resposta imune frente a desafios infecciosos.

Aditivos fitogênicos podem ser utilizados no controle da coccidiose em criações de frangos de corte onde é proibida a utilização de antibióticos e anticoccidianos melhoradores de desempenho.

Agradecimentos.- À Fundação de Apoio à Pesquisa do Estado de São Paulo (FAPESP) pela concessão de bolsa de estudo. À Ajinomoto Nutrição Animal, à Phytosynthese La Phytothérapie animale Titrée e M.Cassab Nutrição Animal pela doação dos produtos testados neste experimento.

\section{REFERÊNCIAS}

Albina J.E., Henry W., King P.A., Shearer J., Mastrofrancesco B., Goldstein L. \& Caldwell M.D. 1987. Glutamine metabolism in rat skeletal muscle wounded with a-carrageenan. Am. J. Physiol. 252:E49-E56.

Ardawi M.S.M. \& Majzoub M.F. 1991. Glutamine metabolism in skeletal muscle of septic rats. Metabolism 40:155-164.

Awaad M.H.H., Abdel-Alim G.A., Sayed K., Kawkab S.S., Ahmed A., Nada A.A., Metwalli A.S.Z. \& Alkhalaf A.N. 2010. Immunostimulant effects of essential oils of peppermint and eucalyptus in chickens. Pakistan Vet. J. 30(2):61-66.

Bartell S.M. \& Batal A.B. 2007. The effect of supplemental glutamine on growth performance, development of the gastrointestinal tract, and humoral immune response of broilers. Poult. Sci. 86:1940-1947.

Blikslager A.T. \& Roberts C. 1997. Mechanisms of intestinal mucosa repair. J. Am. Vet. Med. Assoc. 9:1437-1441.

Caldara F.R., Ducatti C., Berto D.A., Denadai J.C., Garcia R.G. \& Ferreira V.M.O.S. 2010. Glutamina e turnover do carbon na mucosa intestinal de leitões desmamados. Revta Bras. Zootec. 39(12):2664-2669.

Christaki E., Florou-Paneri P., Giannenas I., Papazahariadou M., Botsoglou N.A. \& Spais A.B. 2004. Effect of a mixture of herbal extracts on broiler chickens infected with Eimeria tenella. Anim. Res. 53:137-144.

Crawford J. \& Cohen H.J. 1985. The essential role of glutamine in lymphocyte differentiation in vitro. J. Cell. Physiol. 124:275-282.

Dohms J.E. \& Metz A. 1991. Stress: mechanisms of immunosupression. Vet. Immunol. Immunopathol. 30:89-109.

Ducatti C., Carrijo A.S., Pezzato A.C. \& Mancera P.F.A. 2002. Modelo teórico e experimental da reciclagem do carbono-13 em tecidos de mamíferos e aves. Sci. Agric. 59(1):29-33. 
Evans J.W., Plunkett M.S. \& Banfield M.J. 2001. Effect of an essential oil blend on coccidiosis in broiler chicks. Poult. Sci. 80:258. (Abstract)

Fascina V.B., Souza I.M.G.P., Polycarpo G.V., Carvalho F.B., Silva W.T. \& Sartori J.R. 2011. Efeito dos aditivos fitogênicos e ácidos orgânicos na dieta de frangos de corte sobre a histomorfometria de bursa de Fabrícius. Anais Conferência APINCO de Ciência e Tecnologia Avícola, Campinas, SP. CDROM. (Resumo)

Fascina V.B., Sartori J.R., Gonzales E., Carvalho F.B., Souza I.M.G.P., Polycarpo G.V., Stradiotti A.C. \& Pelícia V.C. 2012. Phytogenic additives and organic acids in broiler chicken diets. R. Bras. Zootec. 41(10):2189-2197.

Giannenas I., Florou-Paneri P., Papazahariadou M., Christaki E., Botsogluo N.A. \& Spais A.B. 2003. Effect of dietary supplementation with oregano essential oil on performance of broilers after experimental infection with Eimeria tenella. Arch. Anim. Nutr. 57(2):99-106.

Glick B. 1957. Normal growth of the bursa of Fabricius in Chickens. Poult. Sci. 35:843-854.

Guimarães E.B. 2001. Histometria, índice apoptótico da bolsa cloacal e catabolismo de anticorpos em frangos de corte em ambiente de conforto e estresse térmico. Tese de Doutorado em Patologia e Clínica, Escola de Veterinária, Universidade Federal de Minas Gerais, Belo Horizonte, MG. 74p.

Hodges R.D. 1974. Histology of the bursa of Fabricius and the thymus. Academic Press, London. p.205-213.

Hodgson J.N. 1970. Coccidiosis: oocyst-counting technique for coccidiostat evaluation. Exp. Parasitol. 28:99-102.

Jamroz D., Wiliczkiewicz A., Wertelecki T., Orda J. \& Skorupinska J. 2005. Use of active substances of plant origin in chicken diets based on maize and domestic grains. Brit. Poult. Sci. 46: 485-493.

Johnson J. \& Reid W.M. 1970. Anticoccidial drugs: lesion scoring techniques in battery and floor-pen experiments with chickens. Exp. Parasitol. 28:30-36.

Loddi M.M. 1998. Aspectos produtivos e qualitativos do uso de probiótico para frangos de corte. Dissertação Mestrado em Zootecnia, Universidade Estadual Paulista, Botucatu, SP. 60p.

Lopes K.L.A.M. 2008. Suplementação de glutamina em dietas iniciais para frangos de corte. Tese de Doutorado em Ciência Animal, Escola de Veterinária, Universidade Federal de Goiás, Goiânia. 73p.

Luna L.G. 1968. Manual of Histologic Staining Methods of the Armed Forces Institute of Pathology. 3rd ed. MacGraw-Will, New York. 258p.

Maiorka A., Boleli I.C. \& Macari M. 2002. Desenvolvimento e reparo da mucosa intestinal, p.113-123. In: Macari M., Furlan R.L. \& Gonzales E. (Eds), Fisiologia Aviária Aplicada a Frangos de Corte. Funep, Unesp, Jaboticabal, SP.

Maiorka A., Silva A.V.F., Santin E., Borges S.A., Boleli I.C. \& Macari M. 2000. Influência da suplementação de glutamina sobre o desempenho e o desenvolvimento de vilos e criptas do intestino delgado de frangos. Arq. Bras. Med. Vet. Zootec. 52(5):487-490.

MICROCAL SOFTWARE ORIGINPRO ${ }^{\circledR}$. 2007. OriginPro 8 SR0 v8.0724(B724) Professional.

Miguel F., Francis C. \& François R. 2009. Effet de l'utilisation de complexes d'extraits vegetaux chez le poulet en croissance, vaccine contre la coccidiose et challenge par une inoculation coccidienne a 14 jours. Anais Huitièmes Journées de la Recherche Avicole, St Malo. (Resumo)

Muniz E.C. 2006. Influência da densidade populacional sobre o peso médio, percentual de calo de patas e histomorfometria da bolsa cloacal em aves (Gallus gallus). Dissertação de Mestrado em Ciência Animal, Universidade Federal do Matogrosso do Sul, MS. 34p.

Murakami A.E., Sakamoto M.I., Natali M.R.M., Souza L.M.G. \& Franco J.R.G. 2007. Supplementation of glutamine and vitamin e on the Morphometry of the Intestinal Mucosa in Broiler Chickens. Poult. Sci. 86:488-495.

Nascimento G.M., Leandro N.S.M., Café M.B., Stringhini J.H., Mello H.C. \& Mascarenhas A.G. 2014. Performance and intestinal characteristics of broiler chicken fed diet with glutamine in the diet without anticiccidials agents. Rev. Bras. Saúde Prod. Anim. 15(3):637-648.
Newsholme P., Procopio J., Lima M.M.R., Pithon-Curi T.C. \& Curi R. 2003a. Glutamine and glutamate - their central role in cell metabolism and function. Cell Biochem. Function 21:1-9.

Newsholme P., Lima M.M.R., Procopio J., Pithon-Curi T.C., Doi S.Q., Bazotte R.B. \& Curi R. 2003b. Glutamine and glutamate as vital metabolites. Braz. J. Med. Biol. Res. 36(2):153-163.

Newsholme P. 2001. Why is L-glutamine metabolism important to cells of the immune system in health, post-injury, surgery or infection? J. Nutr. 5:2515S-2522S.

Newsholme E.A., Crabtree B. \& Ardawi M.S. 1985. The role of high rates of glycolysis and glutamine utilization in rapidly dividing cells. Biosci. Rep. 5(5):393-400.

Piva A., Bach Knudsen K.E. \& Lindberg J.E. 2001. Glutamine in gut metabolism. Gut environment of pigs. 260p.

Podolsky D.K. 1993. Regulation of intestinal epithelial proliferation: a few answers, many questions. Am. J. Physiol. 264:G179-G186.

Reeds P.J. \& Burrin D.G. 2001. Glutamine and the bowel. J. Nutr. 131:2505S2508 .

Rhoads J.M., Argenzio R.A., Chen W., Rippe R.A., Westwick J.K., Cox A.D., Berschneider H.M. \& Brenner D.A. 1997. L-Glutamine stimulates intestinal cell proliferation and activates mitogen-activated protein kinases. Am. J. Physiol. 272:G943-G953.

Rostagno H.S., Albino L.F.T., Donzele J.L., Gomes P.C., Oliveira R.F., Lopes D.C., Ferreira A.S. \& Barreto S.L.T. 2005. Tabelas brasileiras para aves e suínos: composição de alimentos e exigências nutricionais. UFV, Viçosa, MG. 186p.

Sakamoto M.I., Murakami A.E., Natali R.M., Fernandes J.M. \& Souza L.M.G. 2005. Influência da glutamina e vitamina E sobre o desempenho e morfometria intestinal em frangos de corte. Anais $2^{\circ}$ Congresso Latino-Americano de Nutrição Animal (ALANA/CBNA), São Paulo, SP. (Resumo)

Shakeri M., Zulkifli I., Soleimani A.F., Reilly E.L.O., Eckersall P.D., Anna A.A., Kumari S. \& Abdullah F.F.J. 2014. Response to dietary supplementation of L-glutamine and L-glutamate in broiler chickens reared at different stocking densities under lot, humid tropical conditions. Poult. Sci. 93(11):2700-2708

Souba W.W., Klimberg V.S., Plumley D.A., Salloum R.M., Flynn T.C., Bland K.I. \& Edward M. 1990. The role of glutamine in maintaining a healthy gut and supporting the metabolic response to injury and infection. J. Surg. Res. 48:383-391.

SPSS 13.0 for Windows. 2014. Release 13.0. SPSS Inc.

Vasconcelos S.P., Bona T.D.M.M., Pickler L., Hayashi R.M., Sousa T.B.A. \& Santin E. 2010. Uso de óleo essencial de orégano, alecrim, canela e extrato de pimenta no controle de clostridioses em frangos de corte. Anais Conferência APINCO de Ciência e Tecnologia Avícola, Santos, SP. Facta, Campinas. CDROM. (Resumo)

Warner N.L. \& Szenberg A. 1964. The immunological function of the bursa of Fabricius in the chicken. Annu. Rev. Microbiol. 18:253-268.

Williams P. \& Losa R. 2001. The use of essential oils and their compounds in poultry nutrition. Worlds Poult. Sci. J. 17:14-15.

Wilmore D.W. \& Shabert J.K. 1998. Role of glutamine in immunologic responses. Nutrition 14:618-626.

Yaqoob P.O. \& Calder P.C. 1997. Glutamine requirement of proliferating T lymphocytes. Nutrition 13:646-651.

Yi G.F., Allee G.L., Knight C.D. \& Dibner J.J. 2005. Impact of glutamine and Oasis hatchling supplement on growth performance, small intestinal morphology, and immune response of broilers vaccinated and challenged with Eimeria maxima. Poult. Sci. 84:283-293.

Yoo S.S. \& Field C.J. \& McBurney M.I. 1997. Glutamine supplementation maintains intramuscular glutamine concentrations and normalizes lymphocyte function in infected early weaned pigs. J. Nutr. 127:2253-2259.

Young V.R. \& Marchini J.S. 1990. Mechanisms and nutritional significance of metabolic responses to altered intakes of protein and amino acids, with reference to nutritional adaptation in human. Am. J. Clin. Nutr. 51(2):270-289. 